\title{
Molecular Characterization of Porcine Reproductive and Respiratory Syndrome Virus (PRRSv) Isolated From Slaughtered Pigs in Northern Uganda
}

\author{
Peter Oba ( $\sim$ P.Oba@cgiar.org ) \\ International Livestock Research Institute \\ Michel M. Dione \\ International Livestock Research Institute \\ Joseph Erume \\ Makerere University \\ Barbara Wieland \\ University of Bern \\ Christine Mutisya \\ International Livestock Research Institute \\ Linnet Ochieng \\ International Livestock Research Institute \\ Elizabeth A. J. Cook \\ International Livestock Research Institute \\ Frank N. Mwiine \\ Makerere University
}

\section{Research Article}

Keywords: PRRSv, genotypes, porcine, pigs, respiratory, Lira, Uganda

Posted Date: June 9th, 2021

DOl: https://doi.org/10.21203/rs.3.rs-579302/v1

License: (a) This work is licensed under a Creative Commons Attribution 4.0 International License.

Read Full License 


\section{Abstract \\ Background}

A cross sectional study was conducted to determine genotypes of porcine reproductive and respiratory syndrome virus (PRRSv) isolated from slaughtered pigs in Lira district, northern Uganda. The study was conducted from March to September 2019 in three selected slaughter slabs. Pigs brought for slaughter were randomly sampled. At necropsy, lungs were extracted from the thoracic cavity and examined for pneumonic lesions. Seventy-three (73) pigs with gross lung lesions were sampled, from which one hundred and one (101) tissue samples were taken. A real-time reverse transcriptase PCR (RT-qPCR) was used to characterize PRRSv genotypes.

\section{Results}

A total of 20 samples tested positive for PRRSv. The respective prevalence of PRRSv type 1 and type 2 were $24.65 \%(n=18)$ and $2.73 \%(n=2)$ respectively. Of the pigs sampled $(n=73)$, only two pigs, $2.73 \%(n$ $=2$ ) tested positive to both strains. The likelihood of PRRSv detection decreased with pig age, but increased with gross pneumonic pathology.

\section{Conclusions}

This study demonstrated dual circulation of both genotypes in northern Uganda. The association between PRRSv and lung pathology suggests that it may be an important cause of lung disease in pigs in Uganda and hence loss of production. This calls for further investigations on potential economic impacts of PRRSv on pig productivity. These findings contribute to discussions about the need of surveillance and possible vaccination strategies against PRRSv in Uganda.

\section{Background}

In Uganda, pig production has increased over the last few years, from approximately 0.7 million in 1990 to 4.2 million pigs in 2018 due to a rising demand for pork [1, 2]. Pig production in Uganda is increasingly becoming an important economic activity for many households, providing a reliable source of livelihoods. However, disease constraints hinder pig production and productivity in the country [3]. Recent multipathogen studies reveal occurrence of economically important respiratory pathogens such as porcine reproductive and respiratory syndrome virus (PPRSv), Mycoplasma hyopneumoniae (M. hyo), Actinobacillus pleuropneumoniae (App), Leptospira spp. and porcine circovirus (PCV2) type 2 [4-6].

Of the pathogens reported, PRRSv is known to be associated with high economic losses from mortalities, reproductive losses and increased costs of control [7-9]. In general, two genetically diverse strains of PRRSv have been described worldwide, with the European genotype (EU) designated as type 1 (PRRSv-1) 
and the north American genotype, designated as type 2 (PRRSv-2) [10]. Furthermore, there is marked genetic diversity in each of these two genotypes, leading to further classification into virus subtypes [11, 12]. These two genotypes are distinct in their virulence, antigenic characteristics and nucleotide sequences $[13,14]$. This has important implications for immunological responses and vaccine selection, as only incomplete protection can be achieved from heterologous field strains [15]. This diversity of the virus also compounds the challenges of disease control, due to differences in transmission rates, strain pathogenicity and its tendency to persist in infected herds.

In the US, PRRSv is reported to cost the swine industry up to $\$ 560$ million annually, with up to $45 \%$ of these losses due to reduced growth and feed efficiency [7]. Overrall, losses due to PRRSv vary widely depending on epidemiological factors, production systems and farm characteristics. In a Dutch study, losses were found to range from $€ 3$ to $€ 160$ per sow per year [16]. The economic impacts of PRRSv on swine productivity are justification for epidemiologic studies to generate knowledge to guide interventions.

In Uganda, no vaccines are currently in use for control or prevention of PRRSv. In particular, few studies on PRRSv in Uganda have mainly focused on serologic assays, providing evidence for past exposure of pigs to the virus and possible virus circulation. Recent developments in the pig sector in Uganda show increased imports of breeder pigs from countries such as South Africa, where PRRSv has been reported [17]. This poses a threat to the swine population, if no measures to contain virus spread are established. There is no information on the current epidemiological situation regarding PRRSv and its potential impacts on swine productivity in Uganda, due to lack of surveillance.

Despite the availability of several commercial vaccines in Europe, America and Asia to control PRRSv [18, 19], the apparent lack of information on the identity of current PRRSv strains circulating in Ugandan pigs limits their use as effective tools for control and prevention. The aim of this study was to determine prevalence and characterize genotypes of PRRSv isolated from slaughtered pigs in northern Uganda.

\section{Methods}

\section{Study design}

A cross-sectional study was conducted from March to September 2019 in three selected slaughter slabs in Lira district, northern Uganda. Slaughter slabs with the highest daily slaughter capacity ( $\geq 8$ pigs) were selected for the study. Pigs slaughtered in Lira district were sourced from within the district ( 60\%), while the rest were sourced from neighboring districts of Apac, Kole, Amolatar and Pader. Figure 1 below shows a map of Lira district in Uganda where the study was conducted.

\section{Sampling of slaughter slabs and pigs}

During this survey, three slaughter slabs: Teso Bar (Adyel division), Adekokwok (Adekokwok subcounty) and Amach market (Amach subcounty) were selected based on high daily slaughter capacity ( $\geq 8$ pigs). 
In each slab, approx. $40 \%$ of pigs brought for slaughter were randomly selected on each day of sampling. At each slab on average, between 8 to 20 pigs were brought for slaughter per day, which represented approx. 8-12 farms. On each day, a list of all pigs brought for slaughter was made and each allocated a number, which were written on a piece of paper and folded. From this list, random sampling was done. Pig biodata was recorded at ante mortem (sex, age), while gross pathology (postmortem) was recorded as described in a related study (Oba et al., forthcoming). Traders were asked about the source(s) of the pigs, which were recorded.

\section{Sample size determination}

The number of pigs sampled represented approximatly $40 \%$ of all pigs slaughtered monthly in the district (DVO, pers comm). The sample size required for a related slaughter slab survey was determined to be 139 pigs (Oba et al., forthcoming). In a previous study, the seroprevalence of PRRSv in Lira district was found to be $1.7 \%$ [4]. Using this figure, the expected minimum number of infected pigs is three (3). To detect the presence of PRRSv, the following equation was used to calculate sample size [20]:

$$
n=\left(1-(\alpha)^{\frac{1}{D}}\right)\left(N-\frac{D-1}{2}\right)
$$

Where $\mathrm{a}=0.05, \mathrm{D}$ is the estimated minimum number of diseased/infected pigs (3), and $\mathrm{N}$ is the number of pigs sampled in a previous related study (139). Using this equation, the computed sample size was 87 pigs. A sample of seventy three (73) pigs was attained, from which 101 tissue samples were taken. Only lungs with gross pathologic lesions were sampled, normal lungs were not sampled.

\section{Examination of lungs and other tissues for gross pneumonic lesions and sample collection}

At necropsy, the carcass was placed on a clean table, opened with knives to expose lungs and the pleura. The lungs were carefully extracted from the thoracic cavity and placed on a flat, clean surface.

Examination of lungs for gross pneumonic lesion scoring is described in a previous related study (Oba et al. forthcoming). Lesion samples were taken and cut into 0.5-gram pieces, placed in a $2 \mathrm{ml}$ cryovial (Sarstaedt ${ }^{\circledR}$, Germany) containing RNAlater ${ }^{\circledR}$ (Thermo Scientific ${ }^{\circledR}$, USA) tissue stabilization solution. Other observed gross lesions were also recorded.. The cryovial was labelled and then placed in an ice box containing ice packs at $4^{\circ} \mathrm{C}$. To prevent cross contamination, a new sterile surgical blade was used for each pig lung, with disinfection of gloved hands and collection tools using $70 \%$ ethanol between samplings. Hand gloves were frequently changed to minimize the risk of cross contamination.

\section{Tissue sample transport and storage}

After collection, tissue samples were immediately (within 2 hours) transported to the district (Lira) veterinary laboratory for temporary storage in a fridge at $4^{\circ} \mathrm{C}$. Later, samples were transported (in an icebox at $4^{\circ} \mathrm{C}$ ) to Makerere College of Veterinary Medicine (CoVAB), Department of Biosecurity, Ecosystems and Veterinary public health laboratory and stored in a $-20^{\circ} \mathrm{C}$ fridge. An export permit was secured from the Commisioner Animal Health, Uganda and an import permit from the Directorate of 
Veterinary Services of the Republic of Kenya to transfer samples to International Livestock Research Institute (ILRI) Kenya for molecular analysis. Upon receipt of an authorization to export samples, tissue samples were shipped by air in October 2019 to ILRI Nairobi, Kenya. The samples were packaged in an ice box containing ice packs at $4{ }^{\circ} \mathrm{C}$, where upon arrival they were placed in a $-80^{\circ} \mathrm{C}$ fridge for subsequent RNA extraction and complementary DNA synthesis.

\section{PRRSv RNA extraction and real-time reverse transcriptase PCR (RT-qPCR)}

RNA extraction was done using the AllPrep DNA/RNA Mini Kit (cat. no. 80204) according to the manufacturer's protocol (Qiagen ${ }^{\circledR}$, Denmark). A real-time (quantitative) reverse transcriptase PCR was performed in the same laboratory, in March 2020 using the KiCqStart(R) One-Step Probe RT-qPCR ReadyMix ${ }^{\mathrm{TM}}$ Low ROX ${ }^{\mathrm{TM}}$ [21]. Real-time RT-qPCR and complementary DNA synthesis were performed in a GeneAmp ${ }^{\circledR}$ PCR System 7500 Fast version 2.3 (Applied Biosystems ${ }^{\circledR}$ ). The sequences of primers (Macrogen Europe, cat. no. OG200117-237) for full length cDNA synthesis and the dual-labeled Taq-Man probes are as shown in Table 1 below [22].

Table 1

Sequences of primers and dual-labeled probes used in the assay

\begin{tabular}{|llll|}
\hline Genotype & Name & Orientation & Sequence \\
\hline PRRSv-1 & Primer 1 & Forward & 5'-CGA CCA CCT CAC CCA GAC-3' \\
\cline { 2 - 4 } & Primer 1 & Reverse & 5'-CAG TTC CTG CGC CTT GAT-3' \\
& Probe & Genomic & 5'-6-FAM-CCT CTG CTT GCA ATC GAT CCA GAC-BHQ1-3' \\
\hline PRRSv-2 & Primer 2 & Forward 1 & 5'-ATG ATG RGC TGG CAT TCT-3' \\
\cline { 2 - 4 } & Primer 2 & Reverse & 5'-ACA CGG TCG CCC TAA TTG-3' \\
& Probe & Genomic & 5'-HEX-TGT GGT GAA TGG CAC TGA TTG ACA-BHQ2-3' \\
\hline
\end{tabular}

A qPCR master mix was made up of $4 \mu \mathrm{l}$ molecular biology grade water, $1 \mu \mathrm{l}$ of $10 \mu \mathrm{M}$ Forward, $1 \mu \mathrm{l}$ of 10 $\mu \mathrm{M}$ reverse primers, $1 \mu \mathrm{l}$ of $10 \mu \mathrm{M}$ probe and $10 \mu \mathrm{l}$ of KICqStart Master mix (Sigma Aldrich, UK). The master mix was completely mixed by tapping the tube and a quick short spin. This master mix cocktail was adequate for one reaction. The components of the master mix were adjusted to suit the number of samples. The contents of the master mix tube were mixed thoroughly and dispensed $17 \mu$ to each labeled sample and control tubes. An RNA template of $3 \mu \mathrm{l}$ was then dispensed to each tube with a master mix. The tubes were placed in a 7500 Fast Thermalcycler and the program which includes a Reverse Transcriptase (RT) at $50^{\circ} \mathrm{C}$ for $10 \mathrm{~min}$, pre-heating at $95^{\circ} \mathrm{C}$ for $10 \mathrm{~min}$, denaturation at $95^{\circ} \mathrm{C}$ for 30 seconds and annealing at $60^{\circ} \mathrm{C}$ for 1 minute was started. This was repeated for 45 cycles with the RT and preheating occurring just once.

\section{Data analysis}


Strain identification was determined by plotting amplification curves of fluorescence signal detected versus cycle threshold values $(\mathrm{Ct})$. Cycle threshold values of $\leq 42$ were considered positive and $\mathrm{Ct}$ value > 42 were taken as negative. Summary statistics were derived in the R environment for statistical computing, version 4.0 .4 (http://cran.r-project.org/). The relationship between PRRSv positivity age, sex, location and gross pathology was measured using Chi-squared analysis in the epiDisplay package in R.

\section{Results}

Seventy three (73) pigs were sampled, from which 101 tissue samples were taken. Of the pigs sampled $(n=73)$, the prevalence of PRRSv type 1 and type 2 were $24.65 \%(n=18)$ and $2.73 \%(n=2)$ respectively. Only two pigs, $2.73 \%(n=2)$ tested positive to both PRRSv type 1 and type 2 isolates. There was a significant relationship between PRRSv positivity and the degree of lung pathology, Odds Ratio 3.74 (95\% Cl 1.14-15.05). Table 2 below shows a summary of results.

Table 2

Summary of the $\mathrm{Chi}^{2}$ analysis for PRRSv- 1 and PRRSv-2 positive samples collected from pigs in Lira District, Uganda

\begin{tabular}{|c|c|c|c|c|c|}
\hline Variable & Category $(\mathrm{N}=73)$ & $\begin{array}{l}\text { PRRSv-1 } \\
\text { prev. \% (n) }\end{array}$ & $\begin{array}{l}\text { PRRSv-2 } \\
\text { prev. \% (n) }\end{array}$ & $\begin{array}{l}\text { Odds Ratio } \\
(95 \% \mathrm{Cl})\end{array}$ & $\begin{array}{l}\mathrm{Chi}^{2}, \mathrm{df}, \mathrm{p}- \\
\text { value }\end{array}$ \\
\hline \multirow[t]{2}{*}{ Pig sex } & Males $(n=35)$ & $25.71(n=9)$ & $0(n=0)$ & $\begin{array}{l}1.12(0.38- \\
3.32)\end{array}$ & $\begin{array}{l}0.05,1 \\
0.841\end{array}$ \\
\hline & Females $(n=38)$ & $23.47(\mathrm{n}=9)$ & $5.26(n=2)$ & 1 & \\
\hline \multirow[t]{2}{*}{ Pig age } & $\begin{array}{l}\leq 12 \text { months }(\mathrm{n}= \\
48)\end{array}$ & $29.17(n=14)$ & $4.17(n=2)$ & 1 & - \\
\hline & $>12$ months $(n=25)$ & $16.66(n=4)$ & $0(\mathrm{n}=0)$ & $\begin{array}{l}0.46(0.13- \\
1.59)\end{array}$ & $\begin{array}{l}1.53,1 \\
0.216\end{array}$ \\
\hline \multirow{2}{*}{$\begin{array}{l}\text { Gross } \\
\text { pathology }\end{array}$} & $0-24 \%(n=33)$ & $12.12(n=4)$ & $0(\mathrm{n}=0)$ & 1 & - \\
\hline & $25-72 \%(n=40)$ & $35.00(n=14)$ & $5.00(n=2)$ & $\begin{array}{l}3.74(1.15- \\
15.05)\end{array}$ & $\begin{array}{l}3.93,1 \\
0.023^{*}\end{array}$ \\
\hline \multirow[t]{3}{*}{$\begin{array}{l}\text { Slaughter } \\
\text { slab }\end{array}$} & Teso bar $(n=39)$ & $28.20(n=11)$ & $2.56(n=1)$ & $\begin{array}{l}1.30(0.37- \\
5.05)\end{array}$ & - \\
\hline & Adekokwok $(n=26)$ & $23.07(\mathrm{n}=6)$ & $3.84(n=1)$ & 1 & \\
\hline & Amach mrket $(n=8)$ & $12.56(n=1)$ & $0(n=0)$ & $\begin{array}{l}0.49(0.01- \\
5.27)\end{array}$ & $\begin{array}{l}0.936,2 \\
0.626\end{array}$ \\
\hline \multirow{2}{*}{$\begin{array}{l}\text { Origin of } \\
\text { pig }\end{array}$} & Lira $(n=43)$ & $20.93(n=9)$ & $4.65(n=2)$ & 1 & \\
\hline & $\begin{array}{l}\text { Neighboring } \\
\text { districts }(n=30)\end{array}$ & $30.00(n=9)$ & $0(\mathrm{n}=0)$ & $\begin{array}{l}1.60(0.53- \\
4.83)\end{array}$ & $\begin{array}{l}0.37,1 \\
0.37\end{array}$ \\
\hline
\end{tabular}




\section{Discussion}

This study revealed circulation of both type 1 and 2 PRRSv genotypes in northern Uganda. However, PRRSv type 1 was found to be the more predominant genotype detected. These findings also indicate that PRRSv-1 likely to be prevalent elsewhere in Uganda, where its occurrence has not yet been investigated properly. This situation could have adverse implications for swine productivity in the country, herd economic performance and consequently livelihoods, if the virus becomes established in commercial breeding herds. Information about the predominant virus is important for implementing successful interventions for controlling the spread of the virus given the potential economic impacts of PRRSv on swine productivity.

These results showed the likelihood of PRRSv-1 detection decreased with pig age. While this was statistically non significant, it suggested a trend that needs further exploration with a larger sample size. This finding is consistent with the observation that the immune system of swine is able to completely eliminate PRRSv infection over prolonged periods of time, leading to sterilizing immunity [19]. Pigs exposed to PRRSv become resistant to reinfection with a homologous strain, although the level of protection was incomplete [23]. This was also corroborated by a study which found age-dependent resistance to infection, shown by reduced viremia and viral load in the blood of adult pigs compared to younger pigs [24]. In contrast, other studies revealed that PRRSv tends to persist in infected herds [25, 26], suggesting increased likelihood of detection in older pigs. However, this finding was specific for larger herds and where there were increased re-introductions of infected gilts [27]. In the smallholder pig production systems in northern Uganda, most farms were generally small in size (1-3 sows) and the replacements were infrequent, as highlighted in a related study (Oba et al. forthcoming).

The increase in PRRSv detection rates associated with gross pathologic lesions conforms to previous studies. The ability of PRRSv to induce clinical and macroscopic pneumonia, often as a co-infection with other pathogens such as $M$. hyo has been documented [28]. No differences in detection rates between male and female pigs were observed in this study.

Our results are comparable to other studies which reported simultaneous circulation of both PRRSv type 1 and type 2 genotypes in various regions and show increased circulation of PRRSv type 1. In Europe, both types circulate but there is a predominance of type 1, with marked genetic variation among the genotypes [11]. In Asia, studies report the predominance of PRRSv type 1 in China, although the American type 2 has also been documented [29]. In the Republic of Korea, it was found that both type 1 and type 2 strains circulated in pig farms during the period between 2013-2016. However, type 1 PRRSv was reportedly predominant [30].

The information on PRRSv in African countries is limited but there are official reports submitted to OIE by a few countries in Africa (DR Congo, Benin, Burkina Faso, Egypt, Ivory Coast, Nigeria) that document occurrence of PRRSv, although none of these studies reported its genetic diversity or molecular identity [17]. The current situation regarding the PRRSv genotypes circulating on the continent is largely unknown, as the few studies undertaken were based on serologic assays. In southwest Nigeria, a study reported a 
high seroprevalence of PRRSv of 53.8\%, suggesting widespread exposure of pigs to the virus [31]. However, the genotype of the virus was not determined.

In South Africa, the PRRSv strain responsible for the 2004 outbreaks was identified by RT-PCR as type 2 [32]. Our results are contrary to expected since a large number of pigs are imported from South Africa and suggest a different source of the virus in Uganda, since PRRSv type 1 has not been reported in South Africa. The lack of reliable data on pig imports into Uganda limits our understanding of the likely sources of PRRSv introduction into the country. Further studies to understand the introduction and maintenance of PRRSv into Uganda are required. Knowledge gaps remain on the potential distribution of PRRSV strains in other regions of Uganda especially in high pig dense areas, which justify further studies.

The method used to detect PRRSv in this study utilised primers that were designed to simultaneously detect both PRRSv-1 and PRRSv-2. This approach is reported to have high specificity and sensitivity, at differentiating PRRSv-1 from PRRSv-2 isolates [22,33]. This method is reportedly efficient and rapid for large scale detection and differentiation of PRRSv strains. However, this study was limited by the small sample size used and by the fact that the study was undertaken in only one region, implying that results cannot be extrapolated to other regions of the country. Because we sampled only pigs that presented with gross lung lesions, the true prevalence of PRRSv and the distribution of strains in all slaughtered pigs and in the general pig population still remains unknown and possibly is higher to what has been reported here.

\section{Conclusions}

This is the first study to document dual circulation of PRRSv type 1 and 2 genotypes in pigs in Uganda. The relation between PRRSv and severe lung pathology suggests it may be an important and increasing cause of lung disease in pigs in Uganda and hence loss of production. This study reveals PRRSv- 1 is the predominant genotype in circulation in northern Uganda. However, in view of its reported genetic diversity, further characterization of possible PRRSv-1 subtypes and evaluation of their pathogenicity in pigs is justified, as well as investigating circulation of PRRSv in other parts of the country with the aim to establish surveillance. In addition, studies to evaluate efficacy of different control measures, such as vaccination, considering dual circulation of the two genotypes and to quantify their economic efficacies in Uganda are recommended.

\section{Abbreviations}

App - Actinobacillus pleuropneumoniae

CoVAB - College of Veterinary Medicine, Animal Resources and Biosecurity

DVO - District Veterinary Officer

M. hyo - Mycoplasma hyopneumoniae 
PCV2 - Porcine circovirus type 2

PRRSv - Porcine reproductive and respiratory syndrome virus

RT-qPCR - real-time reverse transcriptase polymerase chain reaction

\section{Declarations}

\section{Ethics approval and consent to participate}

This study received ethical approvals from the following institutions: Institutional Review Board (IRB), College of Veterinary Medicine, Animal Resources and Biosecurity, Makerere University (IRB \# SBLS/REC/18/008), Uganda National Council of Science and Technology (UNCST reg no. A590); ILRI's Institutional Research Ethics Committee (IREC no. IREC2018-23) and ILRI's Institutional Animal Care and Use Committee (IACUC2018-22). Prior informed consent was obtained from district local authorities and owners of slaughter slabs before the study commenced.

\section{Consent for publication}

Not applicable

\section{Availability of data and materials}

The datasets used and/or analysed during the current study are available from the corresponding author on reasonable request. Both tissue samples and PCR products for this paper are stored at ILRI laboratory (Lab 5), ILRI campus, Nairobi, Kenya and can be obtained upon request.

\section{Competing interests}

The authors declare that they have no competing interests.

\section{Funding}

The funding received from the German Academic Exchange Service (DAAD) through the International Livestock Research Institute (ILRI) for Peter Oba's PhD research program at Makerere University is greatly appreciated. This research was conducted as part of the CGIAR Research Program on Livestock and is supported by contributors to the CGIAR Trust Fund (www.cgiar.org/URL:http://www.cgiar.org/aboutus/our-funders/). The funding agency had no role in the study design, analysis or preparation of this manuscript.

\section{Authors' contributions}

$\mathrm{PO}, \mathrm{MD}, \mathrm{JE}$ and FNM designed the study, PO collected the data, PO, CM, LO \& EAJC performed molecular assays; PO, MD, FNM, JE, BW \& EAJC contributed to interpretation of results and wrote the manuscript; all authors reviewed and approved the final manuscript for submission. 


\section{Acknowledgements}

We acknowledge the support received from the district veterinary officer Lira district, Dr Anthony Ogwal and the extension officers, Podpodo Cecil and Benard Okello during data collection. We thank owners of slaughter slabs and the butchers for their voluntary consent in this study.

\section{Authors' information}

$\mathrm{PO}$ is a veterinarian with a MSc and a graduate fellow at ILRI Kampala. MMD holds a PhD in veterinary epidemiology. He is a scientist and team leader, herd health at ILRI, based at Dakar, Senegal. JE holds a $\mathrm{PhD}$ in veterinary medicine with over 20 years experience in research and training. JE is a Professor of Veterinary Microbiology, Dept of Biomolecular Resources \& Biolab Sciences, CoVAB, Makerere University. BW holds a PhD in veterinary epidemiology with 20 years experience in research and development cooperation. BW is a team leader at the Institute of Virology and Immunology (IVI), Switzerland. CM and LO are research associates at ILRI Nairobi, Kenya. EAJC holds a PhD and is a scientist, epidemiology at ILRI Nairobi, Kenya. FNM holds a PhD in Veterinary Medicine. FNM is Associate Professor and Chair, Department of Biomolecular Resources \& Biolaboratory Sciences (BBS), CoVAB, Makerere University.

\section{References}

1. UBOS. Statistical Abstract [Internet]. Entebbe; 2019. Available from: https://www.ubos.org/wpcontent/uploads/publications/01_20202019_Statistical_Abstract_-Final.pdf

2. Ouma E, Ochieng J, Dione M, Pezo D. Governance structures in smallholder pig value chains in Uganda: Constraints and opportunities for upgrading. Int Food Agribus Manag Rev. 2017;20:307-19.

3. Muhanguzi D, Lutwama V, Mwiine FN. Factors that influence pig production in Central Uganda - Case study of Nangabo Sub-County, Wakiso district. Vet World. 2012;5:346-51.

4. Dione M, Masembe C, Akol J, Amia W, Kungu J, Lee HS, et al. The importance of on-farm biosecurity: Sero-prevalence and risk factors of bacterial and viral pathogens in smallholder pig systems in Uganda. Acta Trop. Netherlands; 2018;187:214-21.

5. Jonsson L. Emerging Infectious Diseases: using PCV2 as a model of disease transmission dynamics at the livestock-wildlife interface in Uganda. 2013.

6. Eneku W, Mutebi F, Mwiine F, Okwee-Acai J, Ojok L. Porcine Circovirus type 2 - Systemic disease on pig farms and associated knowledge of key players in the pig industry in Central Uganda. Int $J$ Vet Sci Med [Internet]. Elsevier B.V.; 2018;6:178-85. Available from: https://doi.org/10.1016/j.ijvsm.2018.08.004

7. Neumann E, Kliebenstein J, Johnson C, Mabry J, Bush E, Seitzinger A, et al. Assessment of the economic impact of porcine reproductive and respiratory syndrome on swine production in the United States. J Am Vet Med Assoc. 2005;227:385-392.

8. Zimmerman J, Benfield D., Murtaugh M., Osorio F, Stevenson G., Torremorell M. Porcine reproductive and respiratory syndrome virus (Porcine arterivirus). In: Straw BE, Zimmerman JJ, D’Allaire S, Taylor 
DJ, editors. Dis Swine. Ames, lowa: lowa State University Press; 2006. p. 387-418.

9. Holtkamp DJ, Kliebenstein JB, Neumann EJ, Zimmerman JJ, Rotto HF, Yoder TK, et al. Assessment of the economic impact of porcine reproductive and respiratory syndrome virus on United States pork producers. J Swine Heal Prod. 2013;21:72-84.

10. Faaberg K, Balasuriya U, Brinton M, Gorbalenya A, Leung F, Nauwynck H, et al. Family arteriviridae. Virus taxonomy. Ninth report of the international committee on taxonomy of viruses. Amsterdam; 2012.

11. Stadejek T, Larsen L, Podgórska K, Bøtner A, Botti S, Dolka I, et al. Pathogenicity of three genetically diverse strains of PRRSV Type 1 in specific pathogen free pigs. Vet Microbiol. 2017;209:13-9.

12. Kuhn J, Lauck M, Bailey A, Shchetinin A, Vishnevskaya T, Bao Y, et al. Reorganization and expansion of the nidoviral family Arteriviridae. Arch Virol. 2016;161:755-68.

13. Meng $X$. Heterogeneity of porcine reproductive and respiratory syndrome virus: implications for current vaccine efficacy and future vaccine development. Vet Microbiol. 2000;74:309-29.

14. Kapur V, Elam M, Pawlovich T, Murtaugh M. Genetic variation in porcine reproductive and respiratory syndrome virus isolates in the midwestern United States. J Gen Virol. 1996;77:1271-6.

15. Osorio F, Galeota J, Nelson E, Brodersen B, Doster A, Wills R, et al. Passive transfer of virus-specific antibodies confers protection against reproductive failure induced by a virulent strain of porcine reproductive and respiratory syndrome virus and establishes sterilizing immunity. Virology. 2002;302:9-20.

16. Nieuwenhuis N, Duinhof T, van Nes A. Economic analysis of outbreaks of porcine reproductive and respiratory syndrome virus in nine sow herds. Vet Rec. 2012;170.

17. OIE. Porcine reproductive and respiratory syndrome in South Africa. Follow-up report No. 2. Disease Information (Weekly info), 21 September 2006, Vol. 19, No. 38. 2005.

18. Renukaradhya G, Meng X, Calvert J, Roof M, KM. L. Live porcine reproductive and respiratory syndrome virus vaccines: Current status and future direction. Vaccine. 2015;33:4069-80.

19. Murtaugh M, Genzow M. Immunological solutions for treatment and prevention of porcine reproductive and respiratory syndrome (PRRS). Vaccine. 29:8192-204.

20. Dohoo IR, Martin W, Stryhn H. Veterinary Epidemiologic Research. 2nd ed. Charllotetown, Prince Edward Island, Canada: AVC Inc; 2003.

21. Bustin S, Nolan T. RT-qPCR Testing of SARS-CoV-2: A Primer. Int J Mol Sci. 21:3004.

22. Kleiboeker SB, Schommer SK, Lee SM, Watkins S, Chittick W, Polson D. Simultaneous detection of North American and European porcine reproductive and respiratory syndrome virus using real-time quantitative reverse transcriptase-PCR. J Vet Diagnostic Investig. 2005;17:165-70.

23. Shibata I, Moriy M, Yazawa S. Experimental reinfection with homologous porcine reproductive and respiratory syndrome virus in SPF pigs. J Vet Med Sci. 2000;62:105-8.

24. Klinge K, Vaughn E, Roof M, Bautista E, Murtaugh M. Age-dependent resistance to Porcine reproductive and respiratory syndrome virus replication in swine. Virology. 2009;6:177. 
25. Wills RW, Doster AR, Galeota JA, Jung-Hyang S, Osorio FA. Duration of Infection and Proportion of Pigs Persistently Infected with Porcine Reproductive and Respiratory Syndrome Virus. J Clin Microbiol. 41:58-62.

26. Nathues $\mathrm{H}$, Alarcon P, Rushton J, Jolie R, Fiebig K, Jimenez M, et al. Cost of porcine reproductive and respiratory syndrome virus at individual farm level - An economic disease model. Prev Vet Med. Elsevier B.V.; 2017;142:16-29.

27. Evans C, Medley G, Creasey S, Green L. A stochastic mathematical model of the within-herd transmission dynamics of Porcine Reproductive and Respiratory Syndrome Virus (PRRSV): fade-out and persistence. Prev Vet Med. 2010;93:248-57.

28. Thacker E, Halbur P, Ross R, Thanawongnuwech R, Thacker B. Mycoplasma hyopneumoniae Potentiation of Porcine Reproductive and Respiratory Syndrome Virus-Induced Pneumonia. J Clin Microbiol. 1999;37:620-7.

29. Wang X, Yang X, Zhou R, Zhou L, Ge X, Guo X, et al. Genomic characterization and pathogenicity of a strain of type 1 porcine reproductive and respiratory syndrome virus. Virus Res. 225:40-9.

30. Kang H, Yu JE, Shin JE, Kang A, Kim W II, Lee C, et al. Geographic distribution and molecular analysis of porcine reproductive and respiratory syndrome viruses circulating in swine farms in the Republic of Korea between 2013 and 2016. BMC Vet Res. 2018;14:1-11.

31. Aiki-Raji CO, Adebiyi Al, Abiola JO, Oluwayelu DO. Prevalence of porcine reproductive and respiratory syndrome virus and porcine parvovirus antibodies in commercial pigs, southwest Nigeria. Beni-Suef Univ J Basic Appl Sci [Internet]. Beni-Suef University; 2017; Available from: http://linkinghub.elsevier.com/retrieve/pii/S2314853517301695

32. Oosthuizen C. A restrospective study of a Porcine Reproductive and Respiratory Syndrome outbreak in South Africa in 2004. Prod Anim Stud [Internet]. 2010;MMedVet:42. Available from: http://upetd.up.ac.za/thesis/available/etd-06102011-155507/

33. Lurchachaiwong, W Payungporn, S Srisatidnarakul U, Mungkundar C, Theamboonlers A, Poovorawan Y. Rapid detection and strain identification of porcine reproductive and respiratory syndrome virus (PRRSV) by real-time RT-PCR. Lett Appl Microbiol. 2008;46:55-60.

\section{Figures}




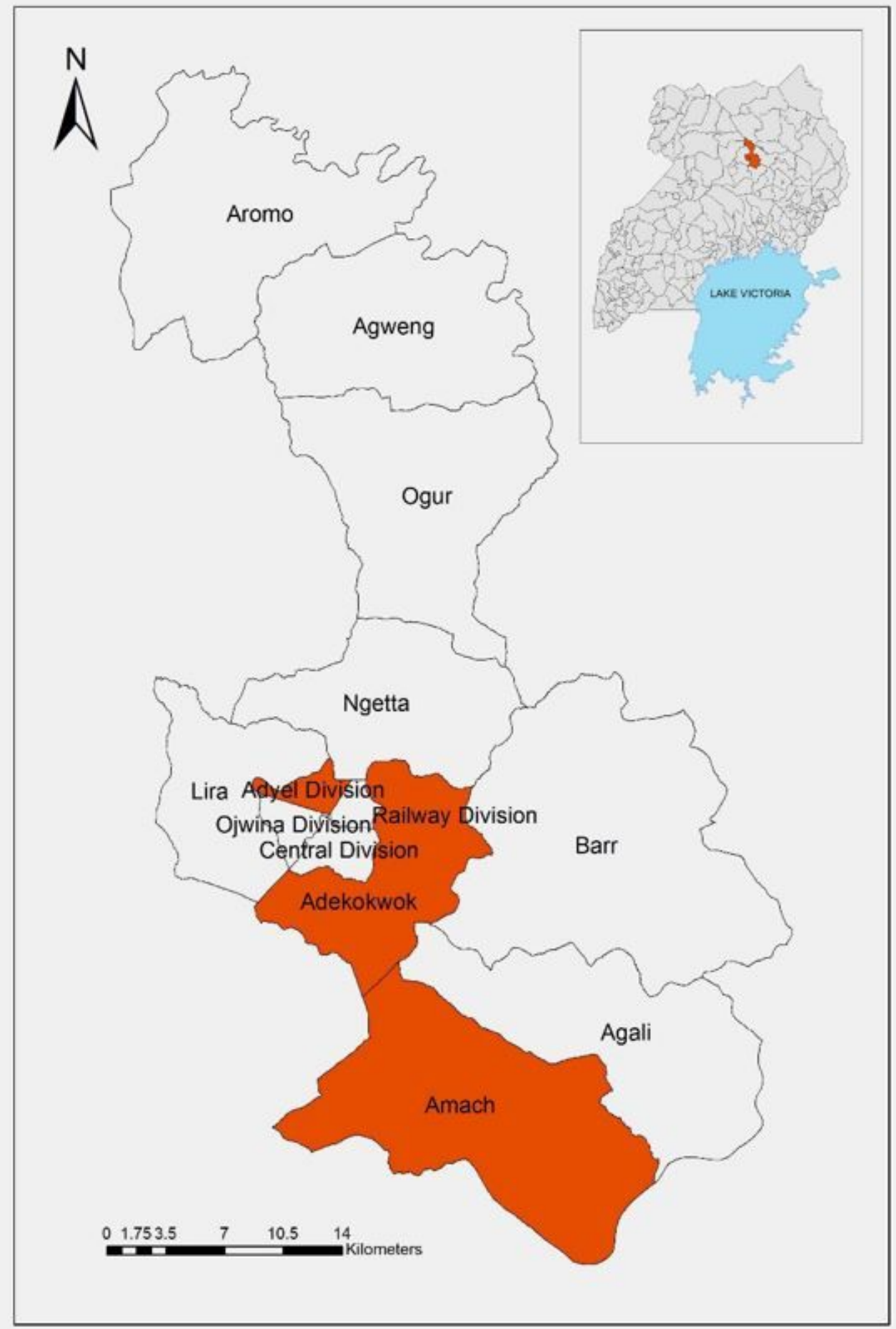

\section{Figure 1}

Map of Lira district Uganda showing study sites: Amach, Adekokwok and Adyel division (Teso bar) Note: The designations employed and the presentation of the material on this map do not imply the expression of any opinion whatsoever on the part of Research Square concerning the legal status of any country, territory, city or area or of its authorities, or concerning the delimitation of its frontiers or boundaries. This map has been provided by the authors. 